Eur. J. Clin. Chem. Clin. Biochem.

Vol. 31, 1993, pp. 75-82

(C) 1993 Walter de Gruyter \& Co. Berlin - New York

\title{
Anomalous Tumour Marker Concentrations in Renal Transplant Patients
}

\author{
By W. G. Wood ${ }^{1}$, J. Steinhoff ${ }^{2}$ and Anne-Christine Kessler ${ }^{3}$ \\ 1 Institut für Laboratoriumsdiagnostik, Klinikum der Hansestadt Stralsund, Stralsund \\ ${ }^{2}$ Klinik für Innere Medizin, Medizinische Universität zu Lübeck, Lübeck \\ ${ }^{3}$ Evaluation Department for Immunology Systems, Boehringer-Mannheim, Tutzing
}

(Received July 15/October 26, 1992)

Summary: Serial serum determinations of the tumour associated antigens carcinoembryonic antigen, tissue polypeptide antigen, CA 19-9, CA 15-3 and CA 125 were performed on 70 patients who were undergoing, or had undergone renal transplantation.

The period of observation ranged from 4 days pre-operative to 708 days post-operative, although daily monitoring was usually carried out during the first $14-35$ days post-operatively.

With the exception of tissue polypeptide antigen, which was analysed with an immunoluminometric assay, all analytes were measured with the Enzymun-Test ${ }^{\circledR}$ System ES-300 using immunoenzymometric assays with colorimetric determination. The interassay coefficients of variation were less than $5 \%$ for the immunoenzymometric assays and $8.7 \%$ for tissue polypeptide antigen, all values being derived from 20 consecutive assays.

Only $8 / 70$ patients with no complications showed normal concentrations for all five analytes. 6/79 patients showed parallel changes of at least three markers. 7/70 patients had transient elevations of at least one marker, whereas $25 / 70$ patients had a continual elevation of CA 125, 9/70 CA 19-9 and 1/70 CA 15-3, although no patient showed evidence of disease. Two patients, each with 2 rejection episodes, showed daily fluctuations up to $100 \%$ for all markers, with the exception of carcinoembryonic antigen. There was no correlation between elevated tumour markers and cytomegalovirus infection.

\section{Introduction}

Despite the vast amount of research on developing in-vitro tests suitable for the early detection of cancer, the lack of diagnostic sensitivity and specificity has prevented such methods being used for screening purposes.

This paper follows up earlier reports on dialysis patients from this laboratory $(1,2)$, as well as from other more recent reports (3) in which elevated tumour marker concentrations were found in the serum of many dialysis patients, without any evidence of malignancy.

As many so-called tumour markers are expressed on the surface of malignant cells $(4-6)$, it was hoped that these tumour associated antigens would be re- leased into the circulation, thus allowing an early and specific detection of malignancies. It was seen however, that the same tumour associated antigens were expressed and released in non-malignant states, thus preventing their use for screening purposes (3).

It had been noticed that elevated levels of tumour associated antigen CA 125 (CA 125) occurred not only in renal haemodialysis (2), but also in advanced liver cirrhosis due to alcohol abuse (1), and the question arose as to whether uraemia and alcoholism may lead to solubilisation of the membrane-bound tumour associated antigens. This could explain the high CA 125 concentrations sometimes found in these patients. If this were the case, then elevated concentrations should return to normal, at least in the dialysis pa- 
tients, after successful renal transplantation and onset of diuresis. This hypothesis formed the basis for this study.

The tumour markers studied were: tissue polypeptide antigen, as this is known to be eliminated renally (1, $2)$, carcinoembryonic antigen and the tumour associated antigens CA 19-9, CA 15-3 and CA 125.

Similar studies, but using single samples from patients with chronic renal failure and under renal haemodialysis, have already been published (7-9), although the results are often different from those found in the present study.

The observation period covered in this study ranged from one week pre-transplant and 708 days after transplantation.

\section{Materials and Methods}

\section{Materials}

Immunoassay kits were purchased from Byk-Sangtec (Dietzenbach, D.) for tissue polypeptide antigen (TPA LIA-mat, immunoluminometric assay) and from Boehringer-Mannheim (Mannheim, Germany) for carcinoembryonic antigen and the tumour associated antigens CA 19-9, CA 15-3 and CA 125 (Enzymun-Test ${ }^{\circledR}$ CEA, CA 19-9, CA 15-3 and CA 125, immunoenzymometric assays).

\section{Methods}

All analytes were measured according to the manufacturers' instructions. The tissue polypeptide antigen assay was measured with a 250 sample semi-automated luminometer (E. G. \& G. Berthold, Wildbad, Germany). The remaining analytes were measured on the Enzymun-Test ${ }^{\circledR}$ System ES-300 (Boehringer, Mannheim).

Table 1 shows the reference ranges for these analytes as established in the routine laboratory of the author (W. G. W.).

\section{Patients}

Seventy patients were studied prospectively over a two year period. All patients who were admitted to the renal transplant unit were taken into the study. The study was carried out between 1989 and 1991 as part of an ongoing study mainly concerned with the evaluation of urinary proteins in such patients, the results of which have already been published in part $(10-12)$.

The five tumour markers were measured daily so long as the patient was in hospital. This covered the peri- and post-transplant periods, as well as periods where complications occurred, usually in the form of rejection episodes, but also in cases of cytomegalovirus infection.

The observation period was from directly before transplantation up to 708 days post-operatively, although the daily monitoring usually covered a period between 14 and 35 days.

\section{Statistics}

Statistics were kept to a minimum, the 2- and 4-field chi-square test being used when required.

Tab. 1. Reference ranges for the tumour markers used in this study.

The values are given for the 95th percentile of 102 clinically healthy volunteers aged between 18 and 72 years of age who were non-smokers and who consumed less than $60 \mathrm{~g}$ alcohol per day. No distinction was made between the sexes. Females on oral contraceptives were excluded from the group, as were persons under regular medication.

Tissue polypeptide antigen $\quad<70 \mathrm{U} / \mathrm{l}$

(TPA)

Carcinoembryonic antigen (CEA)

Tumour Associated Antigen

CA 19-9 (CA 19-9)

Tumour Associated Antigen

CA 15-3 (CA 15-3)

Tumour Associated Antigen CA 125 (CA 125)

* Values above $5 \mu \mathrm{g} / \mathrm{l}$ were taken to be elevated.

+ Values were rounded off for routine purposes.

The reference ranges are only valid for the methods used in this study and have not been related to "cut-off" values with defined diagnostic sensitivity and specificity.

The 95th percentile was taken as the upper limit as many of the subjects had tumour marker concentrations below the lower detection limit of the assays.

\section{Notes upon the analytes measured}

Tissue polypeptide antigen - TPA

This marker is known to be eliminated renally, elevated concentrations being encountered in oliguric and anuric patients $(1,2)$. After onset of diuresis, tissue polypeptide antigen concentrations returned to normal or near normal. Impairment of renal function, for example as in a rejection episode, inevitably led to increased tissue polypeptide antigen concentrations, which correlated with the degree and duration of the episode.

\section{Carcinoembryonic antigen - CEA}

This "classical" tumour marker is often seen to be slightly elevated in patients on chronic haemodialysis (3), and was studied here for this reason.

\section{Tumour associated antigens - CA 19-9, CA 15-3, CA 125}

These markers are known to be elevated in certain patients with impaired renal function $(1-3,7,9)$, although the reports from the literature differ, even for the same marker. All 3 markers are present in epithelial cells.

\section{Assay reproducibility}

The median inter-assay coefficients of variation for the assays carried out on the Enzymun-Test ${ }^{\circledR}$ System ES-300 were less than $5 \%$ over the whole measuring range (derived from 5 control sera covering the whole standard curve for each assay, measured in at least 20 assays) so that sequential analysis of the samples (inclusion in routine assays) was carried out. No difference was seen when all samples from a single patient analysed in one assay were compared with the results obtained as above. 
As this was not the case for tissue polypeptide antigen, the batch analysis of all samples from a single patient was performed as far as was possible. The median inter-assay coefficient of variation for tissue polypeptide antigen was $8.7 \%$ (derived from 20 assays using the same batch of control sera at three concentrations between 50 and $480 \mathrm{U} / 1$ ).

\section{Results}

\section{General comments}

Patients with no clinical complications post-operatively did not necessarily have normal tumour marker concentrations in serum.

Only one patient presented with a clinically/histologically confirmed tumour post-operatively, namely a non-secreting B-cell lymphoma, which was successfully treated.

No apparent correlation was found between the actual clinical condition and the appearance of elevated tumour markers, with the exception of tissue polypeptide antigen and carcinoembryonic antigen. Correlations considered were: transplant rejection episodes, viral/ bacterial infections, medication regimes and cyclosporin toxicity.

\section{Specific cases}

Parallel changes in at least 3 of the four markers (excluding tissue polypeptide antigen)

Six of 70 patients showed parallel changes in at least three of the markers. $4 / 6$ of these patients had at least one elevated tumour marker. Figures $1 \mathrm{a}$ and $1 \mathrm{~b}$ are given as examples of this group.

All tumour concentrations normal in patients with a clinically uneventful post-transplant period

Eight of 70 patients had normal concentrations of all 5 analytes after an uneventful renal transplant operation (figs. $2 a$ and $2 b$ ).

\section{Transient elevation of tumour markers in patients with no complications post-operatively}

Seven of 70 patients had transient elevations of at least one tumour marker post-operatively. Concentrations returned to the reference range for healthy subjects during the first observation period (14-35 days). The elevated markers were: CA 125 (4/7), CA 15-3 (2/7) and CA 19-9 (1/7). Figure 3 typifies this group.
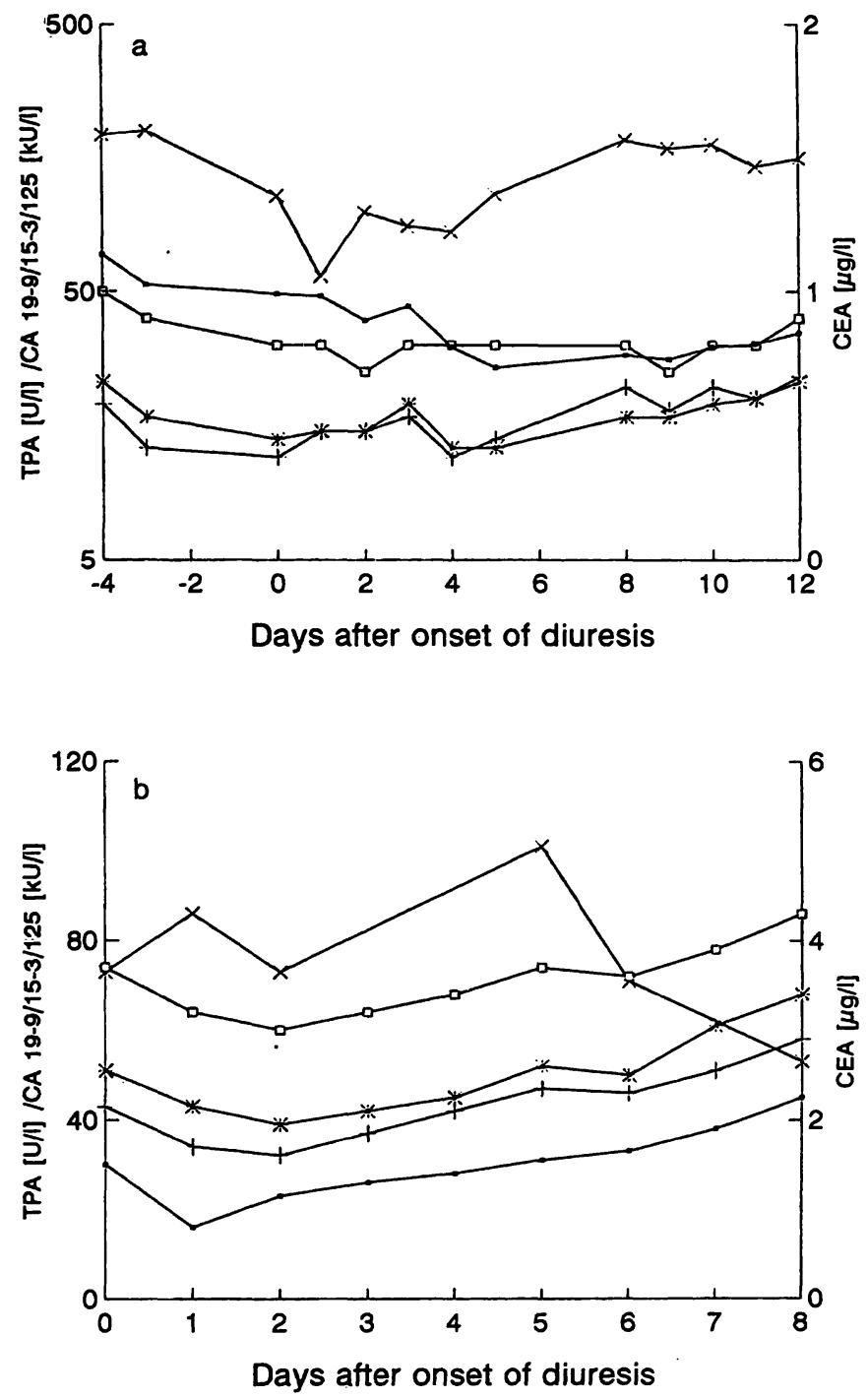

Fig. 1. Parallel course of four tumour markers (patients TP-42 (a) and TP-10 (b)).

These two examples show the parallel course of all tumour markers, with the exception of tissue polypeptide antigen. In figure $1 \mathrm{a}$ the left ordinate is logarithmic to accentuate this trend. This type of course was seen in six of the patients studied. As in the subsequent figures, the abscissa shows the days after onset of diuresis, negative values showing observations prior to this period. Unless stated otherwise, all observations are in the post-operative period.

Key to symbols:

口 - CA 125,

+ - CA 15-3,

* - CA 19-9,

ㅁ - carcinoembryonic antigen,

$x$ - tissue polypeptide antigen.

Consistent elevation of single tumour markers without evidence of malignant disease

Twenty-five of 70 patients showed elevated CA 125 concentrations, $9 / 70$ patients elevated CA $19-9$ and 1/70 patients elevated CA 15-3 concentrations. Figures $4 a-4 c$ show an example for each of these three markers. 

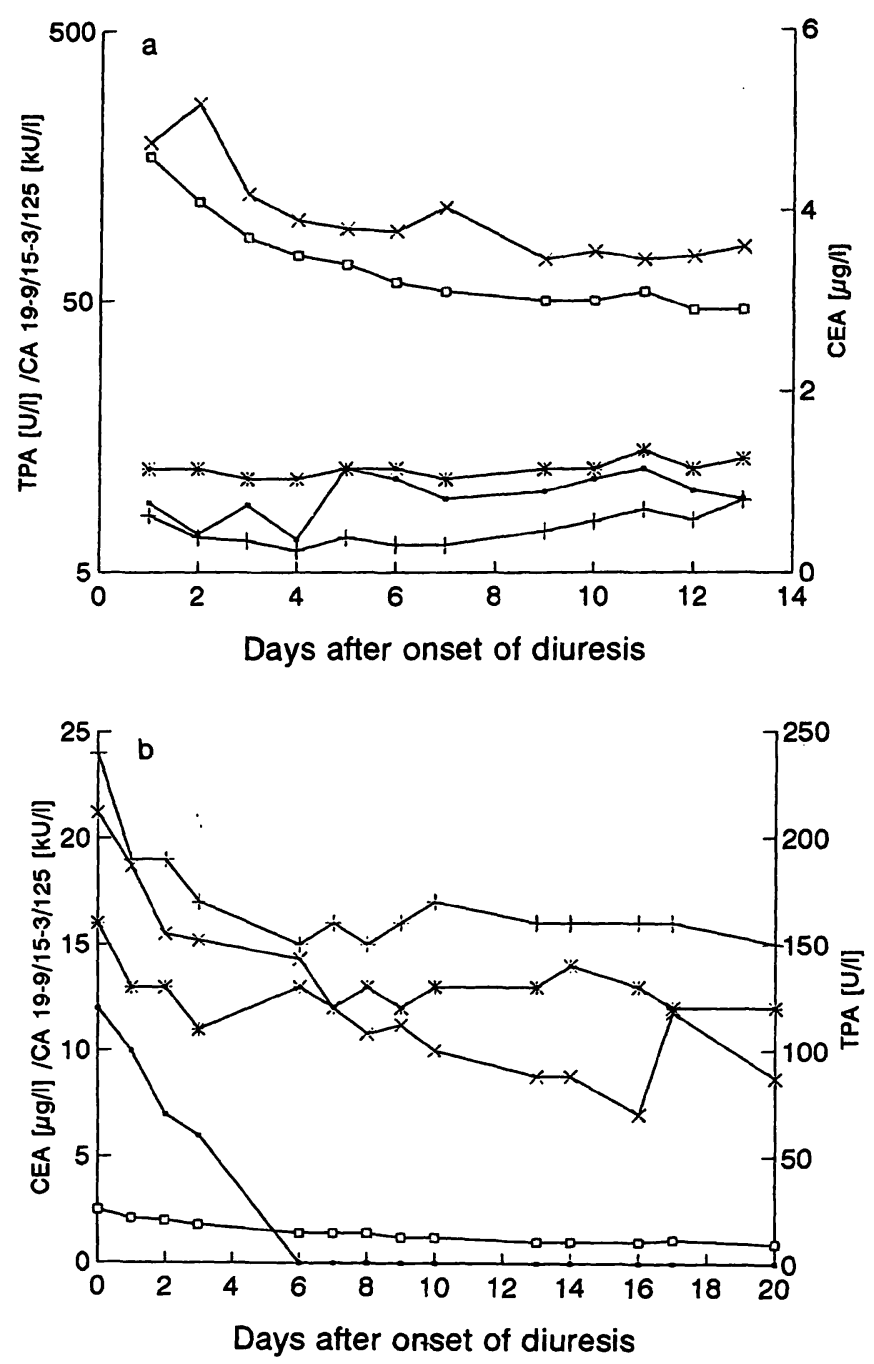

Fig. 2. Normal tumour markers, clincally uneventful (patients TP-08 (a) and TP-28 (b)).

These two pictures show a normal course of events in patients with no elevated tumour marker concentrations. Figure 2a shows a wash-out effect for all analytes. Day 0 is one day prior to operation. Figure $2 b$ shows a similar state of affairs, but where the wash-out phenomenon for carcinoembryonic antigen and tissue polypeptide antigen is much clearer. This picture was observed in eight patients.

Key to symbols:

- - CA 125,

+ - CA 15-3,

* - CA 19-9,

$\square$ - carcinoembryonic antigen,

$x-$ tissue polypeptide antigen.

\section{A case of known malignancy - a non-secreting B-cell} lymphoma (fig. 5)

One patient developed a non-secreting B-cell lymphoma, which was clinically confirmed 30 days after transplantation. The interesting points to note in figure 5 are: a tissue polypeptide antigen trigger, with concentrations rising from 155 to $1030 \mathrm{U} / \mathrm{l}$ within 4 days, despite unchanged diuresis $(2250-2420 \mathrm{ml} /$ $24 \mathrm{~h}$ ) [days 15-18]; an increase in the CA 19-9 concentrations from day $16(58 \mathrm{kU} / \mathrm{l})$ to day $31(222$ $k U / l)$. The other markers showed little or no change

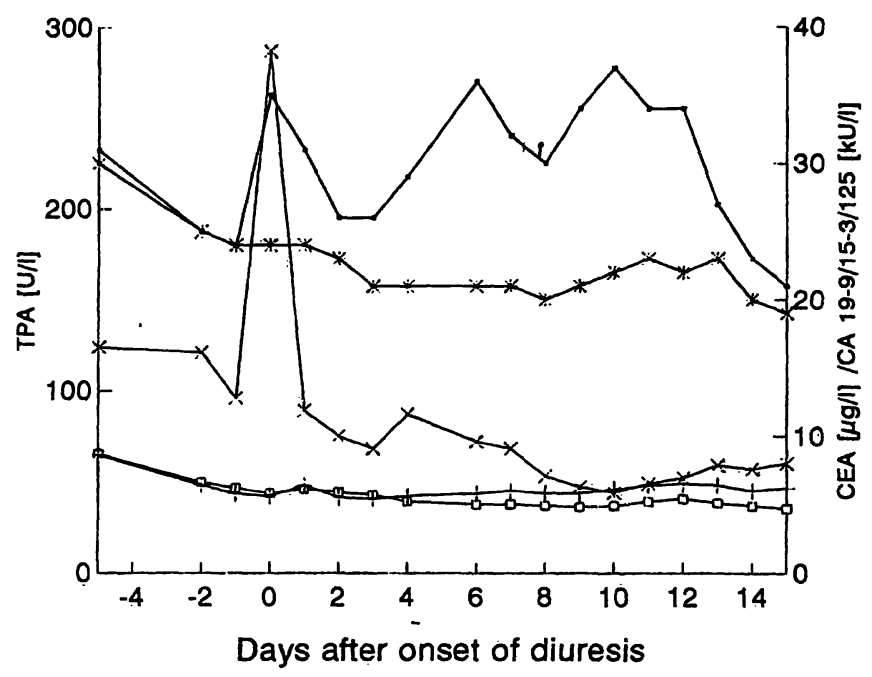

Fig. 3. Transient elevation of tumour markers (patient TP-27). This figure shows transient elevations of carcinoembryonic antigen, CA $19-9$ and CA 125 which were slightly elevated in the peri- and early post-operative phase, but which fell to within the reference range for healthy subjects within three weeks after transplantation. Seven patients presented with a similar picture.

Key to symbols:

- - CA 125,

+- CA 15-3,

* - CA 19-9,

$\square$ - carcinoembryonic antigen,

$x-$ tissue polypeptide antigen.

during this time. It is intersting to note that although the lymphoma was cured (normal blood smear), the CA 19-9 and tissue polypeptide antigen concentrations remained elevated. The serum values on day 708 post op. were: tissue polypeptide antigen $178 \mathrm{U} / \mathrm{l}, \mathrm{CA}$ 19-9 $113 \mathrm{kU} / \mathrm{l}$, CA $15-330 \mathrm{kU} / \mathrm{l}$, CA $125<6 \mathrm{kU} / \mathrm{l}$, carcinoembryonic antigen $3.6 \mu \mathrm{g} / \mathrm{l}$. The concentrations of CA 15-3 were more or less constant and were borderline $(20-32 \mathrm{kU} / \mathrm{l})$. CA 125 , although borderline during the first observation period $(18-34 \mathrm{kU} / \mathrm{l})$, was below the detection limit of the assay almost two years later. Tissue polypeptide antigen remained elevated, despite a normal diuresis. The patient had no signs of malignant disease on day 708 , her transplant functioned normally and there were no clinical complications.

Two cases of transplant rejection (figs. $6 \mathrm{a}$ and $6 \mathrm{~b}$ )

\section{Case 1.}

After intermittent onset of diuresis (days 2-10) the course was uneventful until day 24 when the first signs of rejection were seen (glomerular proteinuria). After successful treatment with methyl prednisolone, the patient was discharged on day 43 . A second rejection episode was confirmed on day 69 , which was successfully treated, the patient being discharged on day 106. During the second rejection episode, CA 19-9 

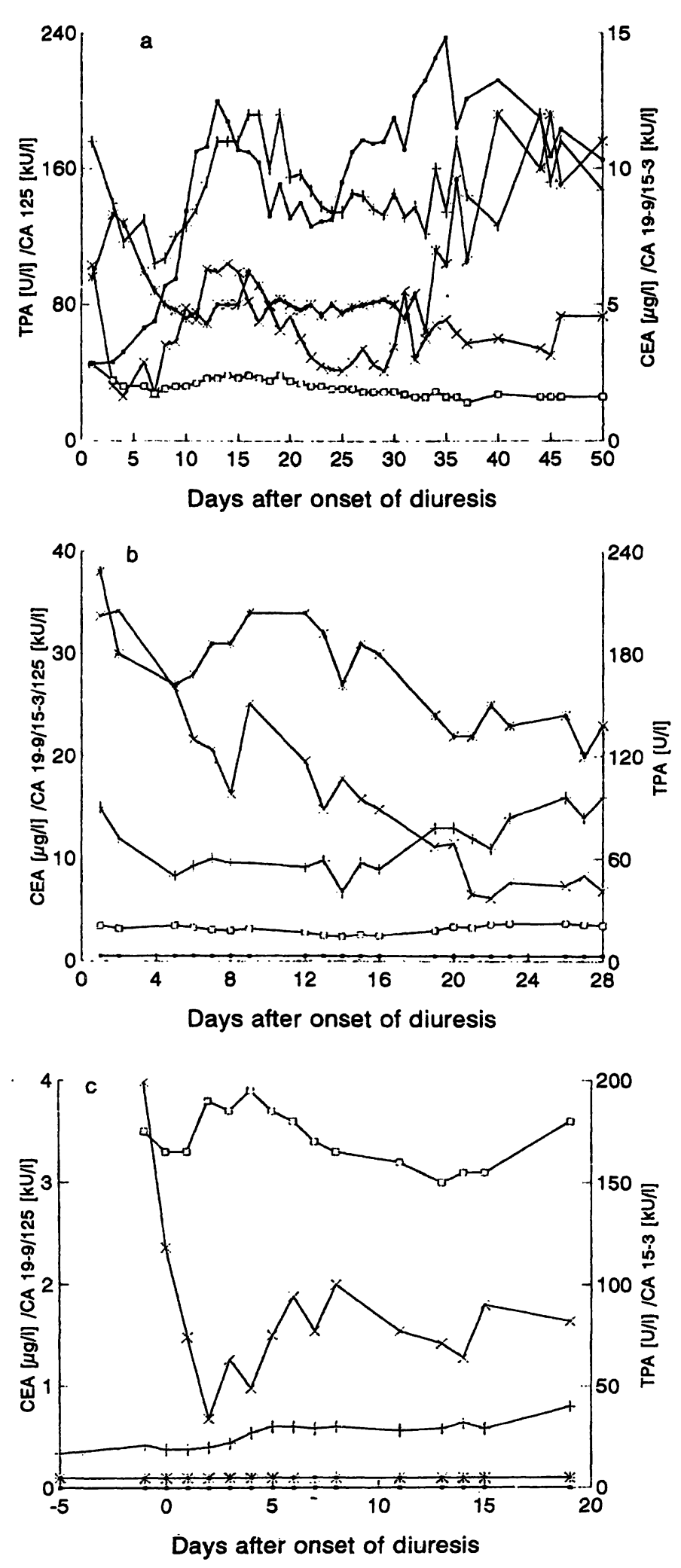

Fig. 4. Persistently elevated single tumour marker concentrations without clinical complications (patients TP-35 (a), TP-12 (b) and TP-01 (c)).

This was the most common picture, 25 of the 70 patients showing such a constellation. Figure $4 \mathrm{a}$ shows the results for CA 125 (25 cases), figure 4b for CA 19-9 (9 cases) and figure $4 c$ for CA 15-3 (one case). The concentrations of CA 125 were on average much higher than for the other two CA-markers. In figure $4 c$ day -5 is 1 day prior to operation.

Key to symbols:

- CA 125, 口 - carcinoembryonic antigen,

+ - CA 15-3, $\quad x$ - tissue polypeptide antigen.

* - CA 19-9,

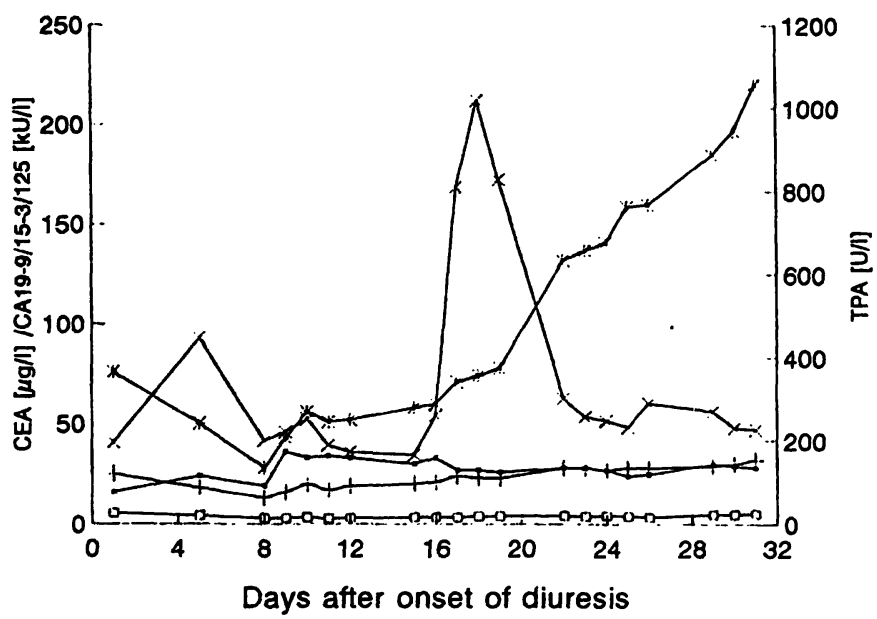

Fig. 5. The isolated case of a malignant process following renal transplantation, the occurence of a non-secreting B-cell lymphoma (patient TP-03).

This shows the course of events of the patient described in the text. Such elevations of tissue polypeptide antigen and CA 19-9 were not seen in any other of the patients observed. It may be that the rapid progression of values is more important than a single observed value. It is most probable that the immunosuppressive treatment after transplantation led to the rapid development of the lymphoma. The serum tumour marker values 708 days after transplantation are listed in the text.

Key to symbols:

a - CA 125,

+ - CA 15-3,

* - CA 19-9,

$\square$ - carcinoembryonic antigen,

$x-$ tissue polypeptide antigen.

and tissue polypeptide antigen concentrations showed daily variations not seen in uncomplicated cases. Concentrations of CA 15-3 were much less affected and CA 125 concentrations first became detectable during the second rejection episode. Carcinoembryonic antigen concentrations fluctuated, although these remained within the healthy reference range. CA 19-9 concentrations were elevated during and after the first rejection episode. Tissue polypeptide antigen concentrations remained within the reference range during both rejection episodes.

\section{Case 2.}

This patient showed no complications until day 55 when transplant rejection signs were seen. After successful treatment (methyl prednisolone), the patient was dicharged (day 70), only to be readmitted on day 96 with similar symptoms. Drugs used for treatment of the second rejection episode included methyl prednisolone and anti-lymphocyte globulins.

The interesting point to note is again the large day to day variation in all tumour markers, with the exception of carcinoembryonic antigen, which remained below $2 \mu \mathrm{g} / \mathrm{l}$ throughout the study period. In contrast 

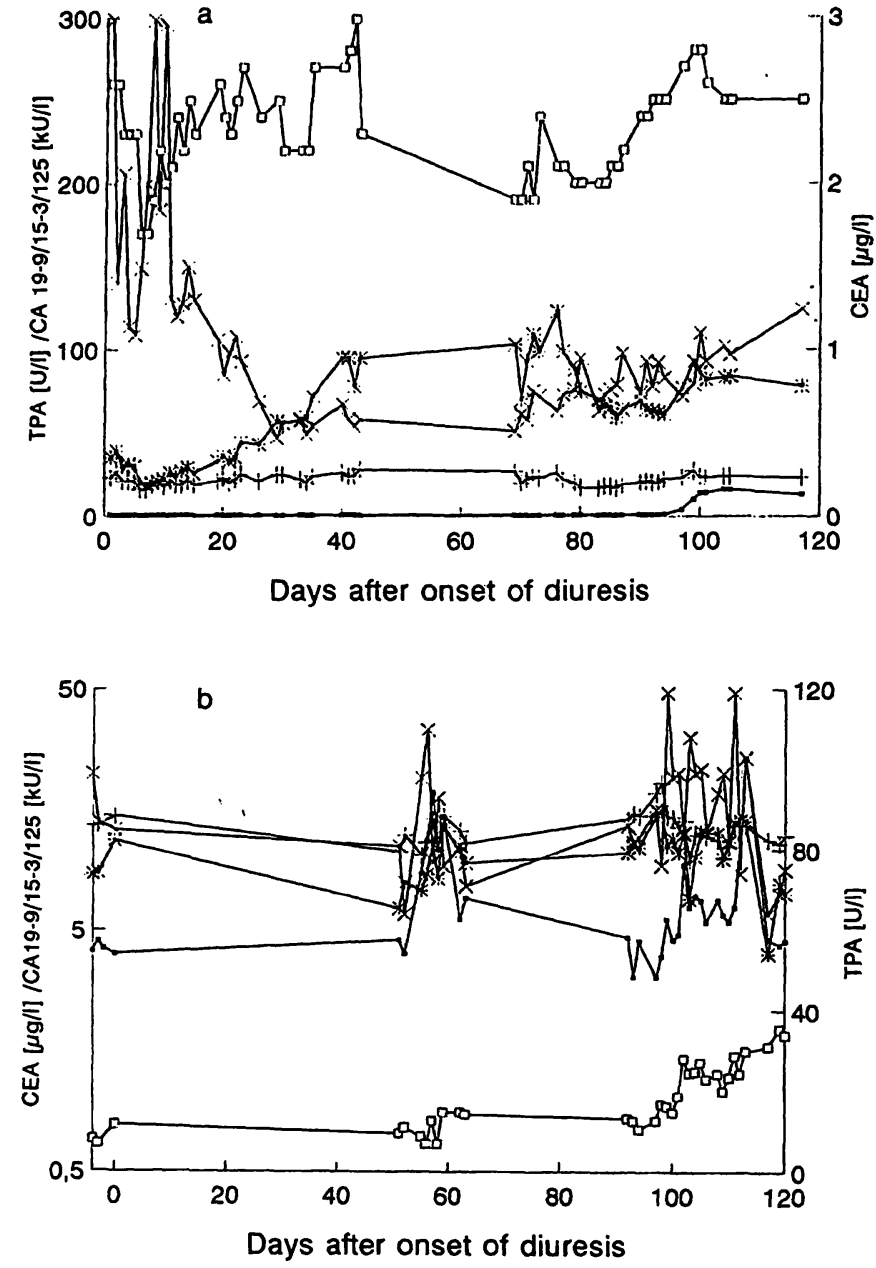

Fig. 6. Rejection episodes after renal transplantation (patients TP-22(a) and TP-16 (b)).

In the 70 patients observed, 29 rejection episodes were monitored, four of which are exemplified in the two patients presented in these figures. The periods connecting the episodes, and lying outside the periods of interest have been included to show any trends in values between the observation periods. The problem periods and rejection episodes in patient TP-22 (fig. 6a) were of longer duration than those in patient TP-16 (fig. 6b), although the amplitude of the variations in the latter patient were greater. Please note the logarithmic left ordinate in figure $6 \mathrm{~b}$, again used for clarity. In figure $6 \mathrm{~b}$ day -4 is 1 day prior to transplantation.

Key to symbols:

- - CA 125,

+- CA 15-3,

* - CA 19-9,

$\square$ - carcinoembryonic antigen,

$x$ - tissue polypeptide antigen.

to case 1 , the tissue polypeptide antigen concentrations oscillated between the upper limit of the reference range and values twice as high. During episodes, variations of up to $60 \mathrm{U} / \mathrm{l}$ occurred from day to day.

\section{Correlation between elevated tumour markers and cy- tomegalovirus infection}

There was no correlation between the incidence of an elevated tumour marker and a cytomegalovirus infec- tion or cytomegalovirus-positive donor organ. This is in contrast to the isolated $\beta_{2}$-microglobulinuria seen in cytomegalovirus infections $(10-12)$.

From the 37 patients, which were positive for cytomegalovirus (either as an infection (17/37) or in the constellation donor cytomegalovirus positive 36/37), 21 had at least one elevated tumour marker (excluding tissue polypeptide antigen). From the remaining 33 patients, who had no cytomegalovirus infection and whose transplanted kidney was also cytomegalovirus negative, 21 had at least one elevated tumour marker. The difference between the groups was not statistically significant.

\section{Discussion}

From this study it cannot be claimed that elevated tumour markers in renal transplant patients is indicative of malignant disease. Only one out of seventy patients had a transient malignancy in the form of a non-secreting B-cell lymphoma, which was no longer evident after treatment.

There was no "wash-out" of tumour associated antigens (CA) at the onset of diuresis. As expected, tissue polypeptide antigen concentrations sank after onset of diuresis. The same was evident for carcinoembryonic antigen, where pre-operatively elevated values (17/70 patients) fell to within the reference range for healthy individuals during 9-14 days after onset of diuresis in $12 / 17$ cases. Of the remaining 5 cases, 3 were concomitant with elevated CA 19-9 concentrations. Carcinoembryonic antigen concentrations above $12 \mu \mathrm{g} / \mathrm{l}$ were not seen pre-operatively.

Although it is known that almost all "tumour markers" can be elevated in non-malignant disease $(1-4$, $13-15$ ), it remains unclear from the literature as to the role of renal insufficiency and the post renaltransplant period in the elevation of tumour markers, which are not purely renally excreted.

Cases et al. (3) describe elevated tumour marker concentrations in 30 patients with chronic renal failure and 36 patients on haemodialysis. They found elevated carcinoembryonic antigen in one third of the chronic renal failure group and in $47 \%$ of the patients undergoing haemodialysis. These figures are considerably higher than those found in the present study, even when considering the pre-transplant values. The same authors found elevated CA 125 concentrations in $18 \%$ of the chronic renal failure and $36 \%$ of the haemodialysis patients, which compare well with the figures in this study (41\%). Cases and coworkers (3) also found elevated concentrations of carcinoem- 
bryonic antigen, CA 50 (similar in structure to CA 19-9) and neuron-specific enolase and squamous cell carcinoma-antigen in chronic renal failure, which led the authors to postulate these markers as being unreliable in such patients. CA $15-3$ and CA 19-9 elevations were much rarer, which coincides with the findings of the present study.

Zeferos et al. (7) have studied tumour markers in renal transplant patients and compared the results with those from healthy controls and patients on chronic haemodialysis. They found that concentrations of $\alpha_{1}$-foetoprotein, CA 15-3 and carcinoembryonic antigen were significantly higher in baemodialysis patients than in controls or renal transplant patients. In contrast, CA 125 and CA 19-9 concentrations were not different in all three groups. Although the findings of the present study are in agreement, as far as carcinoembryonic antigen is concerned, they differ with respect to CA 19-9 and CA 125. Zeferos and coworkers concluded that the two latter markers "can be considered as reliable tumour markers in patients undergoing haemodialysis or kidney transplantation". The same authors query the significance of elevated CA 15-3 concentrations after renal transplantation.

Filella et al. (8) suggest a renal metabolism for carcinoembryonic antigen because of elevated concentrations found in renal insufficiency, although renal elimination could equally well be postulated to explain elevated carcinoembryonic antigen in such patients. The "wash-out" of carcinoembryonic antigen after onset of diuresis, as seen in this study, would tend to support the elimination theory.

Ammon and coworkers (9) found no difference in CA 125 concentrations in healthy subjects and patients with renal insufficiency, although elevated carcinoembryonic antigen $(24 \%>5 \mu \mathrm{g} / \mathrm{l}), \mathrm{CA} 15-3(20 \%>30$ $\mathrm{kU} / \mathrm{l})$ and CA $19-9(14 \%>40 \mathrm{kU} / \mathrm{l})$ concentrations were seen in the same group of patients. As malignant disease had been excluded, Ammon and coworkers concluded that "it seemed likely that the terminal renal insufficiency plays a causal role" in the elevation of tumour markers seen in this group.

In the present study, which comprised over 8500 single measurements of the 5 tumour markers investigated during a long-term study encompassing two years, the results shed some light on the pre-, peri- and post- operative periods in patients subjected to renal transplantation. There are, however many questions still to be answered as to why certain patients have elevated concentrations of certain tumour markers with no evidence of malignant disease.

In addition, it must be stated although the antibodies for the different commercial kits for the tumour associated antigen (CA) tumour markers studied here are supplied by the same firm, this does not guarantee the same results for the same analyte, if different kits are used. This is especially true for CA 19-9 and CA 72-4 (Wood, unpublished observations).

The use of different reference points for defining "normal" and "elevated" values further complicates comparison of results. There are considerable differences between the reference range found for a defined population, the "normal ranges" given by the kit producer, and the "cut-off" values for defined diagnostic specificity and sensitivity.

The conclusions which can be made from this study are that single isolated determinations of CA 125 and CA 19-9 are not reliable indicators of malignancy in renal transplant patients. Because isolated CA 15-3 concentrations are also found in these patients, care must be taken in interpreting elevated concentrations.

Tissue polypeptide antigen concentrations fluctuate with diuresis, a point known for several years $(1,2)$ but still not mentioned in the kit instructions.

Carcinoembryonic antigen concentrations may be slightly elevated before transplantation, but usually return within the reference range for healthy individuals shortly after onset of diuresis, although concomitantly elevated concentrations of carcinoembryonic antigen and CA 19-9 pre-operatively do not always fall after transplantation and onset of diuresis.

Although some categorisation and grouping of results was possible, the study emphasised the individuality of the results from each patient, a point which must be borne in mind when interpreting tumour marker results from such patients.

\section{Acknowledgement}

The authors wish to thank Frau Jutta Jäger, Frau Ulrike Freyher and Herrn Detlev Schult for excellent technical assistance. 


\section{References}

1. Wood, W. G. \& Werner, A. (1984) CEA, TPA and CA 125 levels in different patient groups with benign and malignant disease. Ärztl. Lab. 30, 309-315.

2. Wood, W. G., Bellinger, H., Schulz, E. \& Otte, M. (1984) CA $19 / 9^{\mathrm{TM}}$ - a useful addition to CEA and TPA for tumour diagnosis and follow up in a university hospital? Ärztl. Lab. 30, 105-114.

3. Cases, A., Filella, X., Molina, R., Ballesta, A. M., LopezPedret, J. \& Revert, L. (1991) Tumor markers in chronic renal failure and hemodialysis patients. Nephron $57,183-$ 186.

4. Daoud, E. \& Bodor, G. (1991) CA-125 concentrations in malignant and non-malignant disease (clinical conference). Clin. Chem. 37, $1968-1974$.

5. Yu, Y. H., Schlossman, D. M., Harrison, C. L., RhinehardtClark, A., Soper, J. T., Klug, T. L., Zurawski, V. R. \& Bast, R. C. Jr. (1991) Coexpression of different antigenic markers on moieties that bear CA 125 determinants. Cancer Res. $51,468-475$.

6. Jacobs, I. \& Bast, R. C. Jr. (1989) The CA 125 tumourassociated antigen: a review of the literature. Hum. Reprod. 4, 1-12.

7. Zeferos, N., Digenis, G. E., Christophoraki, M., Alexopoulos, I., Kostakis, A., Gyftaki, H. \& Moulopoulos, S. (1991) Tumor markers in patients undergoing hemodialysis or kidney transplantation. Nephron 59, 618-620.

8. Filella, X., Cases, A., Molina, R., Jo, J., Bedini, J. L., Revert, L. \& Ballestra, A. M. (1990) Tumour markers in patients with chronic renal failure. Int. J. Biol. Markers 5, $85-88$.
9. Ammon, A., Eiffert, H., Weber, M. H., Rummel, J. \& Niemann, J. (1988) Tumor markers in patients with chronic renal failure treated by hemodialysis. A comparison of the antigens MCA, CA 15-3, CA 125, CA 19-9 and CEA. Ónkologie 11, 260-262.

10. Wood, W. G., Herhahn, D., Steinhoff, J., Feddersen, A., Schulz, E. \& Sack, K. (1990) The diagnostic relevance of specific urinary proteins after renal transplantation. Ärztl. Lab. 36, 260-267.

11. Steinhoff, J., Feddersen, A., Preuss, R., Wood, W. G., Fricke, L., Hoyer, J. \& Sack, K. (1992) Quantitative protein determination in urine: Diagnostic value in renal transplant patients. Transplantation Proceedings 24, 362-365.

12. Steinhoff, J., Bühner, U., Feddersen, A., Wood, W. G., Preuss, R., Fricke, L., Faerber, P., Dodt, C., Hoyer, J. \& Sack, K. (1992) C-reaktives Protein im Urin. Dtsch. Med. Wochenschr. 117, 894-899.

13. Nakanishi, Y., Niura, K., Katoh, O., Yamaguchi, T., Kuroki, S., Aoki, Y. \& Yamada, H. (1991) Clinical significance of serum CA 125 in patients with tuberculous pleurisy. Kekkaku 66, 525-530.

14. Matsuda, M., Shimizu, Y., Chikamatsu, E., Takayanagi, K., Ishigure, H., Murakami, S. \& Odani, K. (1991) Role of carcinoembryonic antigen, carbohydrate antigen 19-9 and cytology of bile in diagnosis of biliary and pancreatic cancer. Nippon Geka Gakkai Zasshi 92, 716-721.

15. Haglund, C., Kuusela, P., Roberts, P. \& Jalanko, H. (1991) Tumour marker CA 125 in patients with digestive tract malignancies. Scand. J. Clin. Lab. Invest. 51, 265-270.

Prof. Dr. W. G. Wood

Institut für Klinische Laboratoriumsdiagnostik

Klinikum der Hansestadt Stralsund

Krankenhaus am Sund

Große Parower Straße 47-53

O-2300 Stralsund

Bundesrepublik Deutschland 